\title{
Navigating Trust and Distrust in the Refugee Community of Malta
}

\author{
Luisa Gandolfo ${ }^{1,2}$ \\ Accepted: 11 March 2021/Published online: 1 April 2021 \\ (C) The Author(s) 2021
}

\begin{abstract}
This article considers how trust is constructed in the refugee community of Malta, against the backdrop of ongoing and recurrent unrest in Libya. As social trust is reevaluated, social spaces have become sites of tension where divisions re-emerge along political, ideological, and economic lines. By focusing on the Libyan diaspora, the article presents an insight into the ways that conflict trauma shapes trust-building, and considers the challenges faced by civil society organisations and government bodies in their efforts to facilitate support and community-building on the island. The article is based on 14 interviews conducted in 2015 with members of the Libyan diaspora, and Maltese civil society organisations and government bodies. The interviewees discussed the multifaceted aspects of trust-building, including the legacy of 42 years of political distrust during the regime of the former Libyan leader, Muammar Gaddafi, regional affiliations and divisions, and the continuum of trauma that unfolds in the Maltese Open Centres and in the host community. The findings of the study indicate that there are additional structural impediments that extend beyond the ongoing conflict, including the Maltese detention process, the redrawing of political boundaries around social spaces in the towns, and the role of identity, which present determining factors in the building of social trust. Collectively, these aspects hold implications for integration into the diaspora community on the island, while in the long term, individual recovery from conflict trauma is dependent on the trust-networks that are constructed, or joined, by the refugees.
\end{abstract}

Keywords Trust $\cdot$ Distrust $\cdot$ Refugees $\cdot$ Trauma $\cdot$ Conflict $\cdot$ Libya $\cdot$ Malta

Luisa Gandolfo

k.luisa.gandolfo@abdn.ac.uk; https://www.linkedin.com/in/luisagandolfo/

1 Department of Sociology, School of Social Science, University of Aberdeen, Edward Wright Building, Dunbar Street, Aberdeen AB24 3QY, Scotland

2 Aberdeen, Scotland 


\section{Introduction}

The corpus on migrant experiences at sea, and specifically in the Mediterranean, offers significant insights into the complexities of crossing to islands such as Malta, as well as the policies that determine its approach to asylum and support (Klepp, 2011; Tondini, 2010). As an island close to the Libyan and Tunisian coastlines (just over $1000 \mathrm{~km}$ to the former, and under $500 \mathrm{~km}$ to the latter), Malta was selected due to its position in the Mediterranean, which locates it as a key transit point for refugees departing the Libyan coast. As an equally prominent location for departures by sea to the European mainland, 90\% of migrants and refugees crossed from Libya in 2017 (UNHCR, 2017), while within Libya, between 5000 and 6000 refugees and migrants, many from Eritrea and Somalia, are held in 20 detention centres that are managed by unpaid staff amidst 'scant resources, dilapidated facilities, and multiple security threats' (UNHCR, 2017). Libya's position as a transit state and destination for refugees is not a recent development (UNSMIL, 2016): under the country's former leader, Colonel Muammar Gaddafi, migration was a key component of his domestic and foreign policies (Baldwin-Edwards \& Lutterbeck, 2018; Hamood, 2008; Paoletti, 2011; Tsourapas, 2017). Despite the regime's focus on migration, this has not extended to the implementation of a robust legal framework and given the conflicts in the surrounding region, it has failed to meet international standards (UNSMIL, 2016). In addition to poor conditions at the centres, migrants have also experienced sexual violence, torture, abduction, forced labour, and in certain cases, unlawful death (UNHCR, 2020; UNSMIL, 2016). On an international level, Libya is not a signatory to the 1951 Refugee Convention, ${ }^{1}$ nor the 1967 Protocol, ${ }^{2}$ and as such, it contrasts with Malta, which signed both in 1971.

Given Malta's long history of migration, this article focuses on the Libyan community due to their presence on the island over several generations: for some, the transition has been permanent; for others, Malta has become a second home, to be revisited over the years. For others still, it is the first of many stops, as they flee the First (2011) and Second Civil War (2014) and negotiate life in the Open Centres and towns. While Italy, Spain, Greece, France, Germany, and Britain are also home to Libyan communities, the proximity of Malta, its historical political and economic ties with Libya, and the frequent movement of Libyans between the island and the Libyan mainland for business, leisure, and for sanctuary create a unique context in which the motivation to travel to the island varies by age and class, as much as it is guided by political stability in Libya. Since 2011, the upheaval has reframed social trust along Barbara Misztal's understanding of the concept during unrest, where '[w]ith the disappearance of the old bases of forming social trust and the emergence of more contingent structures and changeable conditions, the reconstruction of trust presents many problems'

\footnotetext{
${ }^{1}$ The 1951 Refugee Convention (also known as the Convention Relating to the Status of Refugees) is the legal document that guides the work of the United Nations High Commissioner for Refugees (UNHCR) and guarantees the right of refugees to be protected from refoulement (being returned to a country in which their life is threatened), to facilitate the provision of travel documents, and to assist in resettlement, among other recommendations (UNHCR, 2010).

2 The 1967 Protocol (known in full as the Protocol Relating to the Status of Refugees) amended the 1951 Refugee Convention by removing the geographical (the 1951 Convention initially was tied to Europe) and time-bound (those who were fleeing 'as a result of events occurring before 1 January 1951') constraints (UNHCR, 2010, 14).
} 
(Misztal, 1996). The conflict in Libya presents once such problem, which has resulted in political divisions not only at a state level but among civilians, too. At the same time, Edna Ullmann-Margalit's spectrum of distrust in which 'the area of 'not to trust' covers the area of 'distrust' along with the no-man's-land of neither trust nor distrust' (Ullmann-Margalit, 2017) provides a useful lens to analyse the experience and perception of distrust. In this paper, political trust is defined as trust (or its absence) in the new regime and its influence on the degree that social trust is nurtured and shared. The convergence of political and social trust during and after unrest has been examined in Lebanon, Northern Iraq, Palestine, and among immigrant communities in Denmark (Alijla, 2016, 2019; Nannestad et al., 2014; Rydgren et al., 2013), and this article contributes to the discourse by analysing the development of trust and distrust in the microcosm of the Libyan community in Malta. To do so, the article is concerned with the question, how is social trust negotiated by Libyan refugees once they arrive in Malta? Drawing on the personal experiences of members of the Libyan diaspora and representatives of Maltese and Libyan civil society organisations (CSOs), the article examines the perceptions and practice of trust, distrust, and insecurity, with attention dedicated to the influence of conflict trauma and support provision.

The article opens with a consideration of the regime of Muammar Gaddafi and the ways that political and social distrust was facilitated by the government as a mechanism of regime preservation. As the distrust percolated into Libyan society, its impact on the fabric of Libyan society is traced to the present day and its influence on the diaspora. Next, the methods are discussed with reference to the ethics of conducting research with refugee communities and the language surrounding the migration discourse on the island. Life in the Open Centres is discussed in the Findings, and the threads of tension are continued into the consideration of the process of relocating from the Centres to the towns, where challenges emerge in the provision of psychosocial support to individuals experiencing conflict trauma. While these parts of the article are concerned with the arrival process, life in the Centres, and relocation to the towns, the final two aspects converge in an assessment of the efforts to build social trust amidst political distrust and trauma. Given the ongoing conflict, the war brings further impediments, though pockets of unity emerge.

\section{Tracing Political and Social Distrust in Libya}

To understand how social trust is practiced in the diaspora, it is necessary to visit the roots of the tension in Libya, where political distrust was nurtured over the decades. When Gaddafi came to rule in 1969, Libya had entered its eighteenth year of independence and the coup d'état that brought regime change by removing the al-Sanussi royal family, then led by King Idris I, occurred amidst a changing social and economic landscape. Although 'unity' and 'the people' were placed at the core of the country's governance, the reality was that both concepts were elusive in practice, and the 'United' Kingdom of Libya was 'an expression of hope rather than a statement of fact' (Pargeter, 2012). Over the ensuing years, the dissonance between rhetoric and practice persisted as the regime strove for a system that would follow the tribal/familial networks and significantly, be people oriented. To facilitate this, Gaddafi introduced the 'Third 
Universal Theory" ${ }^{3}$ that would enable 'the people' to engage with the (soon to be numerous) People's Committees (Vandewalle, 2012).

Having come to power through the military coup, Gaddafi was keen that history would not repeat itself. While he was not deposed until 2011, it was not for want of trying: on 15 August 1975, three members of the Revolutionary Command Council, Omar al-Meheishi, Bashir Hawadi, and Awad Hamza, along with 20 officers, devised a coup against Gaddafi following discontent over austerity measures (Cooley, 1982). Their plans were ultimately discovered, and Hawadi and Hamza were arrested, while Al-Meheishi fled to Tunisia (Cooley, 1982). The formation of the National Front for the Salvation of Libya (Al-Jabha Al-Wataniyya li-Inkadh Libya) in 1981 by Muhammad Mugharyif introduced a long-term opposition movement: after establishing its military branch, the Salvation Forces, it conducted various military operations (Vandewalle, 2012), including a failed attack on the Bab Al-Aziziya compound in Tripoli in 1984 (Pargeter, 2012). Eight years later, the group disseminated Platform for the Future (1992), a draft that mapped the terrain of a post-Gaddafi Libya (Deeb, 1996). In response to these challenges, Gaddafi co-opted the tribal networks that had once suggested opportunities for popular engagement, and instead laid an intricate system of divide and rule that would stimulate a distrust that extended from the state to the street (Brahimi, 2011; El-Khawas, 2013; Vandewalle, 2015). Ultimately, the National Front for the Salvation of Libya would outlive Gaddafi, meeting a quasi-end in 2012 when it became the National Front Party and as its leader, Mugharyif, was appointed Chairman of the General National Congress.

The events of 2011 brought the change needed by the opposition, but the fall of the regime also brought instability and devastated the country's political and social infrastructure. While the Civil War lasted just over eight months, the violence continued when the Second Civil War began in 2014. The interim period (2012-2013) was a false lull, as attacks against heritage sites, Sufi shrines, and the American consulate in Benghazi, continued. The 2011 conflict, while brief in comparison with the current unrest, introduced fresh scars: the United Nations Resolutions 1970 (enabling actions short of force) and soon after, 1973 (allowing all necessary measures under NATO's Operation Unified Protector), have left a complicated legacy. Christopher Zambakari's suggestion that 'The long-term prospects for peace in Libya were sacrificed at the altar of political expediency couched in humanitarian language' (2016) is evidenced by several nuanced studies of the war's aftermath, including Jihan Zakarriya's (2018) study of militarised bodies and sexual and gender-based violence (SGBV). While the intervention was linked to the protection of women, Zakarriya (2018) argues that SGBV remains a serious issue, with women lawyers, human rights activists, journalists, and healthcare providers being primary targets of assassination. Among the civilian population, the United Nations Support Mission in Libya (UNSMIL) and the Office of the United Nations High Commissioner for Human Rights (OHCHR) continue to receive reports of summary executions and unlawful killings by armed groups, with 48 deaths documented between January and November 2019 (UNHCR, 2020). For the

\footnotetext{
${ }^{3}$ Between 1973 and 1979, Gaddafi promoted his concept of the 'Third Universal Theory', which comprised a melange of religious, philosophical, political, and social thought. As Alia Brahimi explains, the theory 'condemned capitalism and communism as exploitative monopolistic systems, and invoked Arab nationalism, anti-imperialism and Islamic socialism to present an alternative vision’ (2011).
} 
migrants passing through the country, detention is not only marked by abuse, violence, and poor conditions but also the dangers of a warzone. In July 2019, 44 migrants died and 130 were injured when the Libyan National Army (LNA) dropped two missiles on the hanger that is also the Tajoura Migrant Detention Centre (HRW, 2020). While the LNA later denied involvement, the bombing highlighted the lax approach to migrant safety - in this case, by failing to evacuate the inhabitants of the hanger (HRW, 2020).

In politics, the exit of the old regime allowed the emergence of coalitions, such as the anti-Islamist Operation Dignity under General Khalifa Haftar in Tobruk, and the Libya Dawn Coalition (or, the National Salvation Government) led by Prime Minister Khalifa al-Ghawil, in Tripoli. In addition (and sometimes alongside) the coalitions, various movements have bloomed, some emerging as branches of global actors, such as Ansar Al-Shari'a and Islamic State of Iraq and Al-Sham, others tied to external, international governments. In the case of the former, Ansar Al-Shari'a operates in Libya alongside a local branch, the Libyan Revolutionaries Operations Room. Similarly, Abu Bakr Al-Baghdadi's Islamic State of Iraq and Al-Sham reached 3000 members in 2015 (Daragahi, 2015). Locally, militias such as the February 17th Martyrs Brigade (named after the first day of fighting in Benghazi in 2011) and the Rafallah AlSahati Brigades receive payment from the government, and as Daragahi (2015) observes, militiamen can expect to receive around $\$ 1000$ per month, a point that could prove challenging for reintegration, if a formal process of Disarmament, Demobilisation, and Reintegration (DDR) is introduced in future.

As allegiances to movements and communities shift, the divisions compound a distrust that predates the recent wars and highlights the importance of understanding refugees' experiences of trust before their journey, as much as during and after (BenEzer \& Zetter, 2015; Lyytinen, 2017). Between the groups, old suspicions ensure that grievances are fresh between the Islamists (who fear a return to Gaddafi era persecution), the Misratans (who have experienced profound conflict trauma), and those in power (who fear losing it) (Daragahi, 2015). As each strives to assert their power, trust gives way to a distrust that is practiced along a spectrum that varies according to the personal interaction (Ullmann-Margalit, 2017) or as a coping and/or protection mechanism (Hardin, 2001, 2004). In Dirk Vandewalle's consideration of Libya's post-2011 future, he questions 'how heavily would the shadow of past legacies weigh on the new Libya [...] how would those legacies also become a shadow of the country's future?' (Vandewalle, 2015). Looking back on the political changes that have shaped Libya, loyalty, trust, and security (of the personal and state kind) have been sacrificed at various points and by all sides, and it is the legacy of this repeated loss that shapes how trust and distrust is practiced in the Libyan diaspora.

\section{Building Trust Amidst Ongoing Conflict?}

There is a rich literature on trust and post-conflict peace-building (Murithi, 2002; Schwegler \& Smith, 2012; Sliep, 2014), and how trust is understood in terms of its impact and practice in the conflict and post-conflict environments (BenEzer \& Zetter, 2015; Lyytinen, 2017). Likewise, studies of social trust among refugee and immigrant communities offer a profound consideration of the pathways to trust-building in destination countries, as well as in the host community. Both Lise Togeby's 2004 
study of the impact of organisational participation on the building of social trust in Denmark among 1.5 generation ex-Yugoslavs, Turks and Pakistanis, and Nannestad et al.'s (2014) examination of the role of cultural and institutional trust among migrants and immigrants, also in Denmark, demonstrate a slow movement towards trust-building, with trust varying by gender and prior experience of institutional trust in their countries of origin. The experience of trust or distrust is carried through the large-scale study of the cultivation of generalised trust among immigrants in Western Europe by Peter Thisted Dinesen and Marc Hooghe (2010), who demonstrate the impact of lower generalised trust in a person's country of origin and the possibilities for host countries to facilitate the building of new trust through integration policies. The variance between the practice of trust in an individual's country of origin and the host state is unpacked in Dinesen and Kim Mannemar Sønderskov's review of the literature on immigrant experiences of trust and the prominence of cultural persistence and experiential adaptation in multiple host country contexts, including the USA, Sweden, and Australia (2018). Against this backdrop, this article contributes to the discourse by exploring the less considered aspects of 'exile' and 'diaspora', which present additional sites of uncertainty. While studies have previously explored trust during and after a conflict, this article interrogates the impact of an ongoing, recurrent conflict, in which the process of establishing social trust is open to disruption (Sliep, 2014, 53). Social trust is a vacillating idea that can be negotiated through generalised, particularised, institutional, thick, and thin social trust, and a person can engage in one, a combination of several, or none of these forms. 'Generalised' and 'particularised' trust are defined by Markus Freitag and Richard Traunmüller as the trust that is placed in strangers versus the trust given to those in our immediate social vicinity, including family, friends, and co-workers $(2009,784)$. Given the radiating circles in which we practice generalised social trust, Freitag and Traunmüller's definition leaves the process open-ended as we accumulate new friends, family members, and co-workers over time. Alternatively, Eric Uslaner roots generalised social trust in our early interactions in life and while it appears 'immune to further societal influence' (Newton et al., 2018, 40; Uslaner, $2002,26)$, it is not static, but rather fluctuates over our life-time in 'an unselective and unspecific manner' (Newton \& Zmerli, 2011, 171).

In the work of both Freitag and Traünmuller (2009), and Stefan Dahlberg and Jonas Linde (2018), 'institutional' trust is defined as the trust that individuals place in state institutions. This trust is based on experiences of the institutions, and in certain cases, it is also influenced by the degree of political trust (Freitag \& Traünmuller, 2009, 799; Dahlberg \& Linde, 2018, 1389). Both Robert Putnam (2000) and Avishai Margalit (2017) provide vivid descriptions of 'thick' and 'thin' trust, with the former including 'strong, frequent' relationships with friends and family, that are cemented through rituals such as marriage vows (Putnam, 2000, 136; Margalit, 2017). In contrast, 'thin' trust is fleeting, lacking the deep bonds of 'thick' trust, yet simultaneously offers a path to wider acquaintances (Putnam, 2000, 136), as well as consolation when the trust is broken, as the sense of betrayal 'is too much of a stretch' (Margalit, 2017). Of those, particularised, generalised, and institutional social trust are relevant to this study, and while they appear distinct, they overlap to create a continuum of social trust that spans particularised, generalised, institutional, and abstract (or general) trust (Misztal, 1996). When particularised trust is practiced, it can facilitate relationships between family members, friends, and a community; where absent, it can fuel mistrust and trigger long- 
term disenchantment (Freitag \& Traünmuller, 2009). Generalised trust, when diminished, can heighten suspicion towards strangers and new environments, and when juxtaposed with institutional distrust, the structures that would ease transition into a host society (such as CSOs, NGOs, and government bodies) are likely to be viewed with trepidation. However, as Eveliina Lyytinen (2017) observes, how mistrust is experienced varies between refugees. In the Libyan diaspora in Malta, individual experiences are shaped as much by the journey from Libya, as they are by determinants such as age, gender, political standpoint, and socio-economic background.

In Lyytinen's study, mistrust is characterised by 'a shortage of social trust', the erosion of trust, and the presence of 'negative feelings, risks associated with over-trust and trust violations' (Lyytinen, 2017, 491-492). Used interchangeably, this article refers to 'distrust', though the traits are shared between the two terms. However, the distinction between trust and distrust is sharp: though it is often assumed that distrust is the result of the absence of trust, this article follows Eri Bertsou's (2019) observation that distrust is a complex phenomenon that varies between theory and practice, as well as the different paths of thought on distrust, which include liberal distrust, warranted distrust, and detrimental distrust (Bertsou, 2019, 216). To fully grasp the implications of each form of distrust, they must first be addressed depending on the context to which they are being analytically applied (Bertsou, 2019). More broadly, the need to recognise the nuanced links between distrust and trust has been reflected by its asymmetry (Ullmann-Margalit, 2017; Hardin, 2001), its capacity to be simultaneously present (Van De Walle \& Six, 2014), and its different outcomes, including Russell Hardin's (2001) observation of trust's ability to facilitate cooperation and distrust's capacity to block or inhibit cohesion.

Although this paper is primarily concerned with social trust and distrust, the political events in Libya have created a link between social trust and political distrust. In this case, the feeling that the state does not advocate or support the interests of its citizens is conducive to political distrust and prompts divisions in the community between those who are seen to hold the power and those who do not (Bertsou, 2019; Misztal, 1996). When applied in the case of the Libyan community in exile, power is accompanied by the threat of violence and divisions emerge along lines of those who pose a threat and those who are threatened.

In Libya, the instability that stimulated institutional distrust was experienced by several groups before 2011 and outlasted their departure from the country. When coupled with conflict trauma and concerns for family members who remain behind, the confluence of trauma and distrust manifests in a detachment from others, suspicion, and lingering fear (Kijewski \& Freitag, 2018). In their study of the long-term impact of the conflict in Kosovo, Sara Kijewski and Markus Freitag (2018) demonstrate the implications for social trust after the Civil War ended in 1999. Perhaps as anticipated, the conflict resulted in lower levels of social trust and inhibited positive social trust (Kijewski \& Freitag, 2018). Moreover, since the perpetrators of the violence were strangers, the lower social trust was directed towards all people, known and unknown alike (Kijewski \& Freitag, 2018). During or after a war, sharing trust is a risk that is shaped from the state-down (Freitag \& Traünmuller, 2009; Lyytinen, 2017), as much as horizontally through local, communal dynamics. As the war in Libya continues, particularised and institutional social trust is eroded at home and abroad as the communal fabric is pressured by factionalism, and while the Gaddafi era has ended, social and political distrust remains. 
If a significant outcome of this is suspicion as a component of survival (Sliep, 2014, 53), does it denote an absence of generalised trust? Perhaps not, as Putnam's 'thick trust' (2000) provides a lens to understand how social trust is practiced in Malta. Embedded in close, personal relationships, thick trust is similar to particularised trust insofar as it is practiced by the individual within a small radius that is restricted to those who have been known for a long time (Freitag \& Traünmuller, 2009; Lyytinen, 2017; Putnam, 2000). In Malta, the 'small radius' can include a limited group bound by a shared hometown; a medium-sized group connected through political ideology, or a slightly larger group of life-long friends who have maintained contact over several years across different countries. In each case, conflict trauma and dis/trust converge and determine how cohesion is practiced and between whom, and political distrust guides the extent to which social trust is possible against a backdrop of ongoing conflict, displacement, and trauma.

\section{Methods}

Guided by Misztal's theory on the reconstruction of trust, this article draws on a thematic analysis of qualitative data to argue that the recovery of trust is complicated by the loss of the old reference points for forming trust; instead, they are replaced with rapidly changing conditions (Misztal, 1996), which unfold in exile and in the country of origin, Libya. With time, the understanding of unity and belonging has changed, at times guided by political events in Libya, at others by movement in the Maltese political discourse. While this study initially focused on Libyan respondents, it became clear that migration to Malta is an issue that incorporates human rights, trauma, psychosocial support, and the work of CSOs and government bodies on the island. Similarly, given the multi-generational experiences of conflict and displacement, gathering data required a recognition of the sensitivity of conducting research with refugees, which as Catriona Mackenzie et al. (2007) observe, includes issues of 'power, consent and community representation; confidentiality; trust and mistrust; harms, risks and benefits; autonomy and agency; cultural difference; gender; human rights and social justice; and in the worst cases, oppression and exploitation' $(2007,300)$. To access the community, purposive sampling was employed, which ensured that the respondents were members of the Libyan community on the island, or representatives of the CSOs that work with Libyan refugees and third country nationals who have passed through Libya en route to Malta. This was done by initiating contact with the only organisation dedicated to facilitating dialogue among Libyans on the island, the Libya Foundation for Rehabilitation, and its members provided connections to prominent members of the community. However, the term 'prominent' is significant here, as those who consented to meet were primarily of an elite background, were active in the political and/or social sphere (both formally and informally), and had been established in Malta for several years prior to the Civil Wars. In turn, they can be viewed to be representative of a select portion of LibyanMaltese society, who contrast with the refugees who have arrived since 2011. In order to reflect the varied experiences of arriving and living in Malta, a wide range of respondents were chosen, including long-term residents, directors of the migrant centres, and representatives of NGO and CSOs working with Libyan migrants in Malta.

Once the interviews began in situ, a snowball technique was adopted and the respondents provided recommendations and introductions to fellow colleagues and 
community leaders. By the end of the visit, 14 semi-structured interviews were conducted at locations chosen by the respondents and lasted between one and three hours. The respondents included members of the Libyan diaspora in Malta, and representatives of local CSOs and government bodies, including the Agency for the Welfare of Asylum Seekers (AWAS), the Tobruk Embassy, aditus, the Foundation for Shelter and Support to Migrants (FSM), SOS Malta, the Libya Foundation for Rehabilitation, and the Malta Red Cross. All the respondents from the organisations occupied senior positions and were chosen due to their extensive experience of working with migrants in Malta, or of leading initiatives in the Libyan community. In August 2015, I was based in Gżira, a town north of Valletta, which allowed access to the Open Centre at Marsa, as well as the offices of the organisations, which are based in Valletta, San Ġwann, Floriana, Santa Venera, and Ta'Xbiex.

Of the interviewees, five are members of the Libyan diaspora who were well-known business owners in Valletta and were active at the social heart of the community. The group was multi-generational and given their varied experiences of conflict and migration, our conversations covered their sense of moving between the island and Libya, the ways that relationships are cultivated among the Libyan diaspora (or not), how trust is perceived, and the role of politics in constructing new, and at times contesting, identities between Libyans in Malta. The intergenerational aspect of the Libyan diaspora meant that the respondents had arrived under varying circumstances: some economically stable, others less so. The recent round of political unrest has brought an increase in both Libyan citizens and third country nationals arriving from the country, and to understand the process of resettling in Malta, eight interviews were conducted with members of Maltese CSOs and advocacy organisations who hold expertise in migration and human rights law.

While the interviews with members of the Libyan diaspora focused on individual experiences of life in Malta, the conversations with representatives of the CSOs concentrated on the challenges within the reception and resettlement processes, including registration, accommodation and life at the detention centres, psychosocial service provision, and resettlement in the towns. Lastly, two interviews were conducted with government bodies, the Tobruk embassy in Ta'Xbiex (representing the internationally recognised House of Representatives) and AWAS in Floriana, who collectively provided insights into the relationship between Malta and Libya, as well as the domestic dimensions of the Maltese asylum process.

\section{Terms and Language}

During the interviews, consideration was given to the terms used in the migration discourse in Malta. While 'refugee', 'migrant', 'asylum-seeker', and 'irregular/regular' appear in legislation and statistics, their use by the media and in political discourse is symbolic and dependent on the context in which the terms are used (Crawley \& Skleparis, 2018; Zetter, 2007). ${ }^{4}$ At a regional level, the language of migration tells the listener as much about the person under discussion, as the standpoint of the speaker

\footnotetext{
${ }^{4}$ For a detailed discussion of the issues around terminology, see Heaven Crawley and Dimitris Skleparis' (2018) analysis of the ways that terms such as 'refugee' and 'migrant' contribute to a 'categorical fetishism' $(2018,49)$ that fails to capture the nuances of migration in the Mediterranean region.
} 
or writer. In Damian Spiteri's study of unaccompanied young male asylum-seekers in Malta, the Maltese term, il-klandestini ('the clandestine ones') is traced to the Italian $i$ clandestini and denotes 'illegal immigrants' (Falzon, 2012; Spiteri, 2012). While the term is not restricted to topics concerning the Mediterranean crossings and features in headlines regarding ICE raids in New York and Italian migration policies in Istria, its use in Malta suggests a certain route taken, and the uncertainties associated with that journey. Reflecting on these terms, this article is guided by the terms inferred by the respondents during our conversations. In doing so, it facilitates a respondent-led approach to the narrative, the objective of which is to emphasise the subjective experiences of members of the Libyan community and the ways that they view daily life on the island.

\section{Access}

The structure of the Libyan community in Malta varied from other diasporic communities on the island due to its underlying schisms and (at the time of writing) lacking a unifying leader. The duty of care to the respondents was foregrounded by the study via a guarantee of anonymity and the application of pseudonyms, as well as confidentiality, since the research took place in an environment where refugees continued to arrive and were experiencing profound trauma. Responding to this, interviews with service providers were favoured due to their extensive understanding of the asylum and resettlement process, as well as the opportunity to place distance between the process of data collection and the refugees in the Centre. Additional consideration was given to the risk of re-traumatisation during the interview process, and in response, the semistructured interviews conducted with long-term residents were reconsidered with a view to who the interviews would be conducted with, and which questions could be asked (and which were to be avoided).

Second, access to Libyans who have arrived since 2011 was limited due to moral concerns regarding the wellbeing of the prospective respondents. As B. Heidi Ellis et al. (2007) note, the vulnerability of refugees is not limited to the warzone: while some might not experience the conflict directly, loss of family, friends, income, and the familiarity of local systems compounds existing trauma as they negotiate their way through the asylum process. While several Libyan refugees were resident in the Open Centres, others had relocated to the nearby towns, and staff at the Centres cautioned that the interviews could induce re-traumatisation. This point was emphasised when discussing female refugees, though restricting the experience of gender-based violence during wartime to women (who are often read as victims and survivors) and positioning men as perpetrators (or non-victims or survivors), risks overlooking cases where the violence is enacted against men, or where women have assumed perpetrator roles (Krause, 2015). In both cases, men and women could be susceptible to trauma in the aftermath, as they reflect on their experiences and actions during the conflict. ${ }^{5}$

\footnotetext{
${ }_{5}^{5}$ Ulrike Krause $(2015,4)$ draws attention to the assumptions made when writing about perpetrators, and victims and survivors, during conflicts, noting that 'most analyses in Conflict Studies and Refugee Studies continue to merely reproduce binary structures of female victims and male perpetrators perpetuating gender stereotypes which contrast female peacefulness, docility, and innocence with male strength, power, and independence. [...] This, however, leads to constructing violence as a part of the male nature, neglecting the diversity of perpetrators and other impacting factors such as female offenders or traumatization and related disorders'.
} 
Recognising the possibilities for trauma among all refugees in the Centre, the interviews were conducted with representatives of the centres and CSOs, all of whom worked closely with the refugees and provided anonymised accounts of the refugees' experiences since arriving in Malta.

\section{Analytical Strategy}

The value of thematic analysis is its capacity to translate raw data into recognisable themes (Boyatzis, 1998), demystify the 'somethings [italics in original]' (Fugard \& Potts, 2016, 745) and elevate the 'creative and interpretive stories' (Braun \& Clarke, $2019,594)$ that emerge from the interviews with the respondents. However, the process of coding themes is intricate: not only due to the range of thematic areas but also the impetus behind the designation of titles that capture the essence of the exchanges (Braun \& Clarke, 2006, 2019). Much like a mosaic, each node and its nested themes symbolise tiles that contribute to a broader analytical picture, while the process of collecting the tiles is 'non-linear', the result of shuttling between the raw data and the coded themes (Braun \& Clarke, 2006; Nowell et al., 2017). Guided by the observations of Virginia Braun and Victoria Clarke (2006, 2019), Lorelli S. Nowell et al. (2017), and Jennifer Attride-Stirling (2001), after the interviews were transcribed, inductive analysis was conducted via NVivo using six preliminary nodes that were frequently discussed in our conversations, specifically 'community', 'trust', 'movement and migration', 'gender', 'trauma and PTSD', and 'age', which were chosen after the breakdown and analysis of the transcripts (Attride-Stirling, 2001; Braun \& Clarke, 2006). Within the nodes, twelve basic themes (Attride-Stirling, 2001) were nested, including 'home and belonging', 'media and society', 'integration and acceptance', and 'religion', with the latter emerging least frequently.

Following 'community', 'trust' was discussed equally between the CSO and NGO respondents, as well as members of the Libyan community, and their reflections addressed different aspects of trust, including trust between Libyans, between Libyans and the broader Arab community, and between Libyans and the Maltese community. In each case, the accounts touched on the challenges of trust-building, whether due to socioeconomic perceptions of the Libyan community, tribal or religious affiliations that continued from Libya into the diaspora, or the nuanced social networks that are negotiated between Libyans on the island. In contrast to the Eritrean and Ethiopian communities, who were noted for their successful community-building efforts, the Libyan community negotiates a sensitive terrain that is exacerbated by the ongoing conflict. The third node, 'movement and migration' connected to tensions between the Libyan and Maltese communities via the theme 'integration and acceptance', suggesting a connection between arrival and concerns regarding belonging that was shared by both the long-term Libyan residents and the new arrivals. In joint place as the fourth nodes, 'gender' and 'trauma and PTSD' were mentioned as often as each other, at times separately, at others together, as CSO and NGO respondents touched on gendered experiences of migration and gender-based violence, and members of the Libyan community regularly focused on 'trauma and PTSD', rather than gendered experiences of life on the island. Lastly, 'age', albeit infrequently discussed, nevertheless contributed an insight into the generation gap between the long-term Libyan residents (in their sixties and above) and the younger generation, and the tensions marked their 
relationship along socioeconomic or political lines, while contributing a layer of distrust between the two generations.

\section{Findings}

\section{Unity and Division in the Open Centres}

Since the outbreak of the First Civil War, the Libyan community has expanded into two groups: the first includes those who established roots on the island over the decades, whether by working in Malta and/or having a second home. The second group are young, less financially secure, and arrived at the Open Centres with limited connections to the first group. According to several respondents, members of both groups differ from other individuals fleeing Libya, insofar as they exclusively arrive by plane, rather than by boat. However, as Nathalie, a representative of FSM observed, while the statistics do not reflect any Libyans arriving by boat, there is a margin of doubt, since 'if they came by boat, then they are not mentioned in the statistics overall. We've had Libyans in the Marsa Centre, mostly men; even injured'. While the statistics provide a helpful indication of the arrivals, they are not exhaustive, which makes keeping track — even in hindsight - a challenge.

The number of Libyans in the Open Centres has remained steady in the top three residential groups (NSO, 2016), and accounts by staff at Centres such as Marsa indicate that the residents are between 18 and 35 years old, demonstrate a keenness to exit the Centre as soon as possible, and express a strong sense of community that has resulted in the Centre's rules being challenged often, as Bassam, also of FSM, explained, 'In the Libyan room, there are six or seven per room. We try and spread them out, but they move their beds and go back to where they want. It's causing us a problem, because they are changing all the internal rules. They don't want to keep to the rules'. How the rules are tested varies: at times, they are broken to facilitate closeness, at others the abrogation involves violence, whether between ethnic groups, or within Libyan in-groups.

Although violence has occurred in Open Centres, such as Marsa, and in the towns once the residents are resettled, it has been less than anticipated. For representatives of the CSOs who are familiar with the living conditions, the low incident count is surprising, though attention was drawn to the nuances of the violence, which included overtly 'violent episodes' as well as general 'problems' (Oliver, aditus). The journey by members of the Libyan diaspora from Libya to Malta, and from the Open Centres to the towns, provides an insight into a community in flux, working to find stability amidst uncertainty. Within this process, social trust determines how successful the community-building efforts can be, yet at the same time, the drivers of the tensions cannot be disregarded, including the influence of conflict trauma, and past and present political ideologies. As past events converge on the present, the lack of local support networks reveals the challenges confronted by the CSOs and NGOs, including limited leaders from the Libyan community, who would provide a bridge to identify the needs of refugees who have recently transitioned to the towns.

\section{Relocation: Transitions and Challenges}

The understanding that conflict trauma influences the everyday of those fleeing war zones has been widely discussed (Brewer et al., 2018; Kristjánsdóttir \& Skaptadóttir, 
2019; Mironova \& Whitt, 2016), and as the Second Civil War continues, the Libyan case suggests how long-term unrest can shape political memory and the ties built outside the country. In this sense, social dis/trust, trauma, and political memory are connected to the trauma that emerged from the civil wars, and the political tensions which developed over the past four decades, as discussed by Ibrahim, Bassam, and Qaisar.

The country was under Gaddafi for over 40 years, and unfortunately it has not been developed as it should be. When the revolution came, we had the hope that Libya would become a democratic state, and it would develop its potential, particularly its people. [...] On the contrary, he [Gaddafi] destroyed what was beginning to be developed during the Kingdom. [...] All that has affected the psychology of the individual, and that's why I don't find it strange to find that people have become selfish, opportunist; all these bad characteristics come from a long history of over 40 years, because there were no equal chances, no fairness, no equality. (Ibrahim, LFR)

You can see trauma written all over their faces, because they're [the Libyan residents of the Open Centres] very suspicious, and they don't want to have any interaction: they get up, they wash, they wear their berets and caps, and they walk out. They don't want to have anything to do with anyone. (Bassam, FSM)

The [Libyan] community didn't make a civil society, so it is not about rebuilding the state: there was no state for 42 years. (Qaisar, Tobruk Embassy)

The accounts of Qaisar, Ibrahim, and Bassam highlight the connection between trauma and violence, politics and the past, and trust, while the trauma associated with the Libyan Civil War is entangled with memories of the former rule of Gaddafi, as well as anxieties about the legacy of the revolution.

On first sight, the Marsa Open Centre is Spartan, a squat, beige building set in the corner of the harbour, a stone's throw from the water. If the coastal location conjures visions of fishing boats and promenades, then the intersection of Triq is-Salib tal-Marsa and Xatt il-Mollijiet is a muted contrast. The boats are large and industrial, their hulls looming over the sidewalk, while along the road, ship repair businesses ply their trade. A former school deemed unfit for Maltese children (Haughey, 2010), the Centre has a dilapidated military air, the black iron gate suggesting a new fitting and a guard booth that regulates the residents' exit and entry. Inside, each dorm has 16 beds and though the then management, FSM, worked to blend the communities in the dorms, segregation still occurred, particularly among Libyan residents. While the movement of beds suggests a desire for unity among the Libyan residents, Bassam clarified that the segregation could be double-edged as distrust remains among the in-groups, for while 'they will segregate themselves as Libyans from all the others, at the same time, they will segregate among themselves'.

The fighting in Libya is divided between multiple religious and political factions, and the formation of in-groups and out-groups in the Libyan diaspora aligns with Vera Mironova and Sam Whitt's observation concerning the aftermath of conflict and its traumatic legacy (2016). While the authors consider social identity and group conflict in post-conflict Kosovo, links can be drawn with Libya, as in-groups and out-groups are divided along factional lines and past allegiances, such as pro- or anti-Gaddafi 
sentiments. These lines are stimulated by violence that can facilitate in-group bonding by 'tapping into out-group aversions' (Mironova \& Whitt, 2016, 752), and the result is a fragmentation that occurs in multiple spaces, whether by moving beds in an Open Centre dormitory to ensure proximity to compatriots, or self-censorship in cafés, when the conversation turns to politics. As the boundaries are drawn, they determine who is 'in' as much as who is 'out', and identity and allegiances undergo a process of reengraving as new members arrive, settle, or move away from Malta.

While self-segregation occurs at a group level, trauma and the possibilities for its (re)emergence vary between individuals. It is here that challenges are perceptible, as the opportunity to access support is inhibited by the lack of a visible support network. In the Open Centres, support is provided by NGOs and CSOs who have ties to medical professionals, including therapists and psychiatrists, to whom individuals can be referred. However, referral is a complex process and relies on recognising that a person needs assistance, ensuring that trust can be built between the service provider and the receiver, and in the Centres, reaching out to individuals who have withdrawn and working to meet their needs. At this point, the communal environment of the Centres presents a safety-net, as fellow residents observe each other and report concerning behaviour to visiting NGO and CSO workers. For the support workers at the Malta Red Cross, 'concerning behaviour' is broadly defined and encompasses a person withdrawing from the group, drinking shampoo, or self-harming. A phrase that emerged frequently during the interviews was 'the odd cry for help', and while this was used by the support workers to refer to Maltese cases, it appears in accounts of other countries' detention processes, including Britain (Athwal, 2015) and Australia (Fiske, 2016). The continuum of trauma does not end once in Malta nor amidst the 'safety-net' of the Centres, and for the NGO workers, the transition to the towns presented a cut-off point, as well as a dilemma regarding the ways that support would reach those in need. The concern, here, rests with the need to distinguish between monitoring versus being available to check the refugees' well-being at intervals, as the latter places agency with the individuals to seek assistance when needed, in contrast to the (perceived) controlling undertones of being monitored. The process of ensuring this balance prompted interviewees from the CSOs to reflect on the role of the diaspora community and the possibility for support networks to emerge organically. However, community relations during and after a conflict are fragile (a facet of Misztal's 'changeable conditions' $[1996,76]$ ), and because the framework of support is undergirded by trust, its absence complicates the opportunity for communities to provide a sound source of support.

\section{Building Social Trust Amidst Trauma}

As the war continues, the Libyan community negotiates multiple transitions, whether fleeing the conflict or moving to the Open Centres and beyond into the host community. While a conversation regarding trust-building in the diaspora could be premature, Tania Tam et al. (2009) encourage action to be taken sooner, rather than later, since 'entrenched distrust persists well after the actual conflict is resolved. Negative associations that stem from intergroup conflict linger long after the violence itself has stopped and serve to perpetuate distrust' $(2009,45)$. At the time of writing, the violence in Libya has not stopped and the legacy of Gaddafi's rule challenges the development of social trust in the diaspora, as individuals negotiate conflict trauma and displacement. 
The Libya Foundation for Rehabilitation (LFR) works with individuals in Malta and Libya, and given their networks in both countries, they are uniquely placed to trace the impact of the conflict from Libya, to the island, and in some cases, back to Libya. What emerges is a picture of trauma that extends from the individual to the community and the surrounding environment, as Ibrahim (LFR), explained, 'The infrastructure of the country has been destroyed. Building the airport, roads - these can be done easily. But the people who have been destroyed, you can't. Everybody has been traumatised in Libya. Nobody can think properly'. The fragmentation of the state, the destruction of the cities, and the immense loss of life compound the trauma carried by those fleeing the wars. Once in Malta, the fresh wounds complicate efforts by the CSOs to build trust among the residents of the Open Centres. In Bassam's interviews with the residents, trauma, while not named, is nonetheless recognisable.

When interviewing Libyan young people, they know something drastic has happened, but they don't know what happened to them. They are living in this hazy dream, and they blame everybody. But they have gone through tremendous trauma and changes in their lives, and now they find themselves with nothing. And that is very traumatic. (Bassam, FSM).

While other groups were noted for their support networks and leaders, the Libyan case was complicated by the fact that "no Libyan can go to another Libyan for advice, and this is a problem' (Bassam, FSM).

Set against the continuum of trauma, the building of social trust is an important step as conflict erodes trust on multiple levels, including particularised, generalised, institutional, and social trust. When either form declines, its downturn can negatively impact 'the mechanisms that have promoted collective action for the community's well-being [...] [making] it difficult for social groups and the state itself to recover their cohesion after hostilities cease' (Murithi, 2002, 291-292). In the Libyan diaspora, the renegotiation of social trust occurs at multiple points. For some, the Open Centre and its spaces are a microcosm of the conflict. In the dormitories, communal areas and yards, allegiances are formed, boundaries are drawn, traumas are aired or concealed, and social trust is calibrated to the new location, albeit along familiar lines of identity and beliefs. Beyond the Centre, tensions simmer between the older Libyans and the younger, new arrivals, who have settled on the island since 2011. The legacy of the Gaddafi regime has shaped how the older generation (many of whom are long-term members of the island's Libyan community) is viewed by the younger arrivals, and as the new generation reflects on the past four decades, questions of accountability and complicity complicate the trust-building process.

For Amira, a member of the Libyan women's group on the island, assumptions about the older generation's complicity with the Gaddafi regime have stymied efforts to unite the community, despite attempts to establish a connection. Although the age gap is not vast (Amira, who was in her early sixties, defined the 'younger' generation as being in their thirties and forties), the ideological disparity is strong enough to discourage constructive discussion, and with it, the opportunity to clarify the role of Amira's generation in the Gaddafi era.

I find the generation gap very big and it's difficult for me to talk with them. As a matter of fact, I am prepared to talk to them, but they don't like to. They think we 
come from the old regime, from the old schools of Gaddafi. [...] It's not true: I

lived under Gaddafi, but I have never been a part of that system.

In our broader conversation, Amira highlighted the tensions between the generations and added lines of politics, faith, and economic stability. Among the recent arrivals, the schisms emerge from the civil wars along lines of pro- or anti-Gaddafi supporters, conservative versus liberal approaches to religion, and the tension between the unrecognised General National Congress embassy in Hal Balzan, and the internationally recognised Tobruk government in Ta'Xbiex. The conflict has exacerbated divisions along political, religious, and socioeconomic lines, with each division presenting a stumbling point for trust-building and, subsequently, the provision of support, whether from Maltese CSOs and NGOs, or from within the community. More widely, social distrust envelopes daily life and the reticence to open oneself fully to acquaintances plays out in the social spaces of the island, where informal conversations carry subliminal tensions concerning the topics covered and who is participating in the exchange.

\section{Politics, Risk, and Community}

In addition to the Libyan community, Malta also hosts communities from Eritrea, Somalia, Palestine, Lebanon, and Syria. Although the Eritrean and Somali communities were perceived to be strongly engaged with organisations such as FSM and SOS Malta, ${ }^{6}$ several respondents noted that the Libyan community was loosely structured and less inclined to participate in the events organised by the CSOs and the leaders of other communities. While this can be linked to a reduction in social trust due to the conflict, it is also shaped by additional factors, including the host society.

It's a pity that no one has yet taken the [initiative]. Well, not 'no one', but they [the Libyan community] haven't opened themselves up to assistance. So, you can reach out to individuals, but not as a group, because as a group they are very suspicious of each other. (Bassam, FSM)

The problem they are facing, interestingly, is that because they are Libyan, they are suffering from the discrimination that is a remnant from the attitude that Malta had towards Libyans back in the 1970s and 1980s. When they approach government services, including as refugees, asking for assistance, they tend to be shrugged off. [...] People look at them as the Libyans of the 1980s, and they are suffering from that, because they are not taken to be credible, they are taken to be criminals, crooks, someone here just for employment purposes and not really refugees, and it's quite horrible to hear. (Oliver, aditus)

\footnotetext{
${ }^{6}$ During fieldwork, it was discernible that secular and faith-based CSOs worked towards an inclusive atmosphere with events that were innovative and frequent. In this respect, there was a sense of cohesion, with contact points, favourite venues for socialising and shopping, and occasions that brought together those who had been on the island for several years with those newly arrived. Through the events, knowledge was exchanged via informal networks regarding access to assistance, health care, and legal advice, which would be taken up by the relevant CSOs and government bodies.
} 
Although public engagement seemed lower, this does not suggest a lack of community spirit overall: rather, it is a balance that is determined by an individual's politics, as much as the tension between national and regional identities. Such tensions are guided by the circumstances at hand, as Bassam observed during his years at the Open Centres, where the residents would define themselves as 'Libyans', albeit from a particular area ('Libyan from Benghazi' or 'Libyan from Tripoli'). While the regional identity is foregrounded, the residents were nonetheless bound by their overarching Libyan identity, which manifested via the fine line between being 'a close-knit community, yet very suspicious of one another' and 'the only time that most of them have come close to identifying themselves as Libyan as a group, is when one of them is attacked, or one of them has a quarrel with another nationality' (Bassam, FSM). While social trust is carefully given, loyalty depends on the adversary — an approach that evokes the Arabic saying, 'me against my brother, my brother and I against my cousin, and all of us against the stranger'. Where politics emerges, the regional lines become visible as 'there's a group in these small groupings, [but] very small. Still, they are very suspicious of each other' (Bassam, FSM). The vignette provided by Bassam draws on years of working with young, male Libyan arrivals at the Open Centres, yet a similar picture emerged from respondents who did not pass through the Open Centres, but integrated into Maltese society directly — a route frequently taken by those of a stable socioeconomic background.

For these respondents, suspicion parlayed into a self-consciousness that manifested when meeting friends in social spaces; a wariness accompanied by the knowledge that politics could be spoken among friends, yet the space (often a café or restaurant) could hold compatriots who differed in their outlook, as Dawoud, a long-term Libyan resident of Malta who travelled between Libya and the island, explained,

We are divided along political lines. Some of us are pro-Misrata, some of us are against Misrata; some are pro-Gaddafi, some are against Gaddafi, and this has created many cracks in the Libyan community. It's unfortunate. I only talk to people I trust are on my side. They are pro-democracy.

It's only when you sit with people that you know and trust, that you can relax. It's why I don't sit in other cafés [than this one]. If I sit with you and there's another table of Libyans, I can't speak the same way, and about the same things, that I am talking to you about, now.

Dawoud's account evokes Edna Ullmann-Margalit's (2017) spectrum of distrust as the social sphere introduces a fluidity to the experience of distrust as the extent to which it is practiced depends on the location and inhabitants of the space around the speaker (in this case, Dawoud). Dawoud's inability to 'speak the same way' suggests that while Malta provides a haven from the Civil War, the distance between those in the diaspora and the unrest in Libya remains narrow. At the same time, the boundaries that mark the factional areas in Libya are mapped onto the urban landscape, prompting a renegotiation of social spaces writ small and local. As the community expands and the conflict continues to evolve in Libya, the local boundaries that encircle coffee shops and hotel bars 'acquire a life of their own' (Galton, 2003) creating a slippage between the reality of entering a coffee shop in Sliema and the memory of a boundary in, for example, Tripoli. In this sense, the opportunity to disengage from the conflict by relocating to 
Malta is thwarted by the inability to speak freely in social spaces, even when surrounded by friends. The result is a cautious approach to conversation that is guided by concerns about confrontation in situ, as well as for family members who remained in Libya. This was illustrated in an anecdote by Dawoud, who experienced increasing intimidation every time he published an editorial.

The more I spoke and the more I wrote, the more the threats I received. They knew the name of my wife and son, and they told me that they would get me, my wife, and they would take my son from his school. This started from the minute that I got back to Libya [from Malta]. I went to the police, but nobody could give me support. If me and my family were caught, I don't know where we would end up.

A while ago, I was on a work assignment [abroad], and when I went back to the hotel, I saw the same messages, "we know that you are away", "we know that you're out of the country", "we know your wife is alone".

Dawoud's decision to relocate to Malta was guided by several incentives, including the large Libyan community, a Libyan school for his children, and business ties, yet despite a change in location and regime, the conflict remained close. To negotiate this, thick social trust is practiced by moving within the 'small radius' of friendship groups, in which personal relationships are gauged through likeminded approaches to politics and faith, and a sense of close belonging is cultivated through social activities held in spaces that are read as 'safe'.

As our conversation continued, Dawoud drew comparisons with other communities on the island, such as the Tunisian community, whom he viewed as being 'open and free' since the Tunisian revolution in 2011. While Libya's transition differs from Tunisia (the latter 'not revolutionary per se, but 'refo-lutionary', a mix of revolutionary movements and reformist path' [Bayat, 2013, 272]) — the contrast is noticeable in Dawoud's perception of the social interactions of Tunisians and his Libyan compatriots: 'When I sit with people from Tunisia, I sometimes feel jealous of them. They don't have these suspicions - they are free. Then I ask myself, why do we Libyans have to be like this?'. The freedom that Dawoud sees in the public interactions of his Tunisian friends is contrasted with the limited freedom experienced by the Libyan community. If Malta was anticipated to bring freedom, the expectation has been tested by social media posts and newspaper editorials, as much as by overheard conversations in cafés. Far from being freeing, writing about the conflict and discussing it in the public sphere (both online and offline) is done with the understanding that the words could bring repercussions, and in this sense, social spaces, such as the local café, are no longer safe spaces, and the thick social trust that is shared between close friends is carefully given.

\section{Conclusion}

This article provides an insight into how social trust and distrust is bound with conflict and trauma that is carried beyond the warzone. In particular, it was guided by Misztal's (1996) understanding of social trust during unrest and Ullmann-Margalit's (2017) 
spectrum of distrust, as each responded to the possibilities for social trust to rupture amidst sudden (and often traumatic) change, as well as the emergence of distrust that is not homogenous, but rather in flux and dependent on the complex relationships between individuals, communities, and the state (Ullmann-Margalit, 2017). Since the complexity, in the case of the Libyan community, is shaped by the trauma of the conflict, the article considered the ways that CSOs, NGOs, and government bodies in Malta address the trauma through support provision, and the implications that this has for trust to be fostered in the diaspora community. In both cases, recovery from trauma and the (re)construction of trust - in all its forms - is an ongoing process that is punctuated by transitions that can be physical (such as relocation), emotional (including loss, grief, and frustration), psychological (for example, PTSD), and social (encompassing economic challenges, community engagement or isolation, and personal security). In Malta, the NGOs, CSOs, and government bodies showed a keenness to assist, yet their efforts are challenged by the closure of the Open Centres, the capacity to identify individuals in need of assistance, and the limited visibility of community leaders in the Libyan diaspora on the island. In this sense, while NGOs such as SOS Malta provide a bridge through which support is accessed by integrating community leaders into their organisation, the lack of leaders in the Libyan community suggests that such a bridge would, for now, be untenable. By extension, the evidence gathered by this study suggests that the opportunity to assist traumatised individuals through psychosocial provision is stymied, while on a broader level, trust-building is fragmented as old divisions remain and social occasions that would tentatively facilitate unity remain elusive.

The findings that emerged from the interviews demonstrated how social trust is negotiated in the Libyan community against a backdrop of tensions that follow political and religious lines. At times, this has resulted in self-censorship, as the interviewees regulate their social interactions in the towns, including what topics are covered in their conversations, who they meet with, and where they meet. The latter ('where') is notable for its multi-site specificity, as the online sphere is an equally fraught location that can bring threats, as well as kindle connections. In the towns, the interviewees explained how boundaries are mapped onto the urban landscape, and a fresh geographical ontology is created. No longer following the lines of Libyan cities and regions, the boundaries trace around coffee shops, hotel bars, restaurants, and religious spaces. As the lines are drawn and re-drawn, the boundaries present 'a symbol for the territory it delineates' (Galton, 2003). In this case, Libya is reimagined on a smaller scale in Valetta, Sliema, and Gżira, and other areas.

Given these fractures, Timothy Murithi's call to restore 'broken relationships, through the involvement of the family, community, and even the nation as a whole' (2002, 291) is heartening, yet, as the findings indicate, it is not easily brokered. As Yvonne Sliep observed at the beginning of this article, peace must include peacebuilding on the social bonding, social bridging, and the social linking level (2014, 55), while recognising that suspicion 'becomes part of survival' (53). To an extent, the interviewees indicated that the multi-level approach has been attempted and connections have been pursued through 'awareness, political and intellectual talks and dialogue' (Amira, Libyan Women's Group) that are organised by the older generation of Libyans. However, the evidence gathered by this study demonstrates that this continues to be slow progress, as the conflict is ongoing, and individuals continue to be under threat while overseas. 
Beyond the Libyan diaspora in Malta, members of the island's NGOs, CSOs, and government bodies expressed the nuances of delivering psychosocial support provision to residents of the Open Centres, as well as those who have departed for the towns. Both the continuum of trauma, social and political distrust, and in-group fragmentation emerged as key challenges to the development of social trust, and while the Libyan community could begin a dialogue in future, individual conflict trauma might not heal as quickly in the short term. To an extent, the evidence gathered in this study indicates that these uncertainties are recognised by the CSOs and NGOs, as they also navigate the shifting terrain of support provision and the resources that are made available to them. To do this, concrete projects aimed at the Libyan, refugee, and host communities by CSOs and NGOs encompass cultural engagement, such as the You Are What You Eat festival organised by aditus and the Valletta-based gallery, Blitz, which draws connections between Malta's traditional dishes and their origins in the WANA region; professional development short courses by the Libya Foundation for Rehabilitation that include cognitive behavioural therapy (CBT), children's mental health, and mental health in the classroom, and lastly, advocacy training by the Jesuit Refugee Service's Our Voice project, which trains asylum seekers and migrants to raise awareness of the challenges faced by their community. For now, this analysis indicates that cooperation between the organisations and the refugee community leaders (where available) could provide a best practice model, and as the CSOs and NGOs develop mechanisms to engage with migrants and refugees on the island, they do so amidst ongoing local and global transformations that are inextricably bound to social and political distrust.

Acknowledgements I particularly thank members of the Libya Foundation for Rehabilitation and FSM, who dedicated their time to being interviewed. In addition, my special thanks to members of the Libyan community, SOS Malta, aditus, AWAS, and Red Cross Malta, for their warmth, time, and profound insights.

Funding This work was financially supported by the Society for Libyan Studies.

Open Access This article is licensed under a Creative Commons Attribution 4.0 International License, which permits use, sharing, adaptation, distribution and reproduction in any medium or format, as long as you give appropriate credit to the original author(s) and the source, provide a link to the Creative Commons licence, and indicate if changes were made. The images or other third party material in this article are included in the article's Creative Commons licence, unless indicated otherwise in a credit line to the material. If material is not included in the article's Creative Commons licence and your intended use is not permitted by statutory regulation or exceeds the permitted use, you will need to obtain permission directly from the copyright holder. To view a copy of this licence, visit http://creativecommons.org/licenses/by/4.0/.

\section{References}

Alijla, A. (2016). Between inequality and sectarianism: Who destroys generalised trust? The case of Lebanon. International Science Journal, 66(219-220), 177-195.

Alijla, A. (2019). Political division and social destruction: Generalized trust in Palestine. Contemporary Arab Affairs, 12(2), 81-104.

Athwal, H. (2015). 'I don't have a life to live': Deaths and UK detention'. Race \& Class, 56(3), 50-68.

Attride-Stirling, J. (2001). Thematic networks: An analytic tool for qualitative research. Qualitative Research, $1,385-405$. 
Baldwin-Edwards, M., \& Lutterbeck, D. (2018). Coping with the Libyan migration crisis. Journal of Ethnic and Migration Studies, 45(12), 2241-2257.

Bayat, A. (2013). Life as politics: How ordinary people change the Middle East. Stanford University Press.

BenEzer, G., \& Zetter, R. (2015). Searching for directions: Conceptual and methodological challenges in researching refugee journeys. Journal of Refugee Studies, 28(3), 297-318.

Bertsou, E. (2019). Rethinking political distrust. European Political Science Review, 11, 213-230.

Boyatzis, R. E. (1998). Transforming qualitative information: Thematic analysis and code development. Sage Publications.

Brahimi, A. (2011). Libya's revolution. The Journal of North African Studies, 16(4), 605-624.

Braun, V., \& Clarke, V. (2006). Using thematic analysis in psychology. Qualitative Research in Psychology, $3(2), 77-101$.

Braun, V., \& Clarke, V. (2019). 'Reflecting on reflexive thematic analysis', Qualitative Research in Sport. Exercise and Health, 11(4), 589-597.

Brewer, J. D.; B. C Hayes; F. Teeney; K. Dudgeon; N. Mueller-Hirth; S. Lal Wijesinghe (eds.). (2018) The sociology of everyday life peacebuilding. Springer International Publishing.

Cooley, J. K. (1982). Libyan sandstorm. Sidgwick \& Jackson.

Crawley, H., \& Skleparis, D. (2018). 'Refugees, migrants, neither, both: Categorical fetishism and the politics of bounding in Europe's 'migration crisis'. Journal of Ethnic and Migration Studies, 44(1), 48-64.

Dahlberg, S., \& Linde, J. (2018). Socialization or experience? Institutional trust and satisfaction with democracy among emigrants in different institutional settings. Journal of Politics, 80(4), 1389-1393.

Daragahi, B. (2015). Libya: From euphoria to breakdown. Adelphi Series, 55(452), 39-58.

Deeb, M. K. (1996). Militant Islam and its critics: The case of Libya. In J. Ruedy (Ed.), Islamism and secularism in North Africa (pp. 187-201). Palgrave Macmillan.

Dinesen, P. T., \& Hooghe, M. (2010). When in Rome, do as the Romans do: The acculturation of generalized trust among immigrants in Western Europe. International Migration Review, 44(3), 697-727.

Dinesen, P. T., \& Mannemar Sønderskov, K. (2018). Cultural persistence or experiential adaptation?: A review of studies using immigrants to examine the roots of trust. In E. M. Uslaner (Ed.), The Oxford handbook of social and political trust. New York: Oxford University Press.

El-Khawas, M. A. (2013). Libya's revolution: A transformative year. In J. Davis (Ed.), The Arab spring and Arab thaw: Unfinished revolutions and the quest for democracy (pp. 61-93). Routledge.

Ellis, B. H., Kia-Keating, M., Yusef, S. A., Lincoln, A., \& Nur, A. (2007). Ethical research in refugee communities and the use of community participatory methods. Transcultural Psychiatry, 44(3), 459-481.

Falzon, M. A. (2012). Immigration, rituals and transitoriness in the Mediterranean Island of Malta. Journal of Ethnic and Migration Studies, 38(10), 1661-1680.

Fiske, L. (2016). Human rights, refugee protest and immigration detention. London: Palgrave Macmillan.

Freitag, M., \& Traünmuller, R. (2009). Spheres of trust: An empirical analysis of the foundations of particularised and generalised trust. European Journal of Political Research, 48(6), 782-803.

Fugard, A. J. B., \& Potts, H. W. W. (2016). 'Shine bright like a diamond'? A reply to Braun and Clarke'. International Journal of Social Research Methodology, 19(6), 745-746.

Galton, A. (2003). On the ontological status of geographical boundaries. In M. Goodchild, M. Duckham, \& M. Worboys (Eds.), Foundation of geographic information science. Taylor and Francis.

Hamood, S. (2008). EU-Libya cooperation on migration: A raw deal for refugees and migrants? Journal of Refugee Studies, 21(1), 19-42.

Hardin, R. (2001). Distrust. Boston University Law Review, 81(3), 495-522.

Hardin, R. (2004). Distrust: Manifestations and management. In R. Hardin (Ed.), Distrust. Russell Sage Foundation.

Haughey, A. (2010). Dislocations: Participatory media with refugees in Malta and Ireland. In H. L. Skartveit \& K. J. Goodnow (Eds.), Changes in museum practice: New media, refugees and participation (pp. 1-17). Berghahn Books.

Human Rights Watch (HRW). (2020). 'Libya: Events of 2019'. World Report 2020. Accessed 13 Oct 2020. https://www.hrw.org/world-report/2020/country-chapters/libya\#868c1e.

Kijewski, S., \& Freitag, M. (2018). Civil War and the formation of social trust in Kosovo: Posttraumatic growth or war-related distress? Journal of Conflict Resolution, 62(4), 717-742.

Klepp, S. (2011). A double bind: Malta and the rescue of unwanted migrants at sea, a legal anthropological perspective on the humanitarian law of the sea. International Journal of Refugee Law, 23(3), 538-557.

Krause, U. (2015). A continuum of violence? Linking sexual and gender-based violence during conflict, flight, and encampment. Refugee Survey Quarterly., 34, 1-19. 
Kristjánsdóttir, E. S., \& Skaptadóttir, U. D. (2019). "I'll always be a refugee": The lived experience of Palestinian refugee women of moving to a small society in Iceland. Journal of Immigrant \& Refugee Studies, 17(3), 389-404.

Lyytinen, E. (2017). Refugees' 'journeys of trust': Creating an analytical framework to examine refugees' exilic journeys with a focus on trust. Journal of Refugee Studies, 30(4), 489-510.

Mackenzie, C., McDowell, C., \& Pittaway, E. (2007). Beyond 'do no harm': The challenge of constructing ethical relationships in refugee research. Journal of Refugee Studies, 20(2), 299-319.

Margalit, A. (2017). On betrayal. Harvard University Press.

Mironova, V., \& Whitt, S. (2016). Social norms after conflict exposure and victimization by violence: Experimental evidence from Kosovo. British Journal of Political Science, 48(3), 749-765.

Misztal, B. (1996). Trust in modern societies: The search for the bases of social order. Blackwell Publishers.

Murithi, T. (2002). Rebuilding social trust in Northern Uganda. Peace Review, 14(3), 291-295.

Nannestad, P., Tinggaard Svendsen, G., Thisted Dinesen, P., \& Mannemar Sønderskov, K. (2014). Do institutions or culture determine the level of social trust? The natural experiment of migration from non-western to western countries. Journal of Ethnic and Migration Studies, 40(4), 544-565.

National Statistics Office (NSO), Malta. (2016). Demographic review 2014. National Statistics Office.

Newton, K., \& Zmerli, S. (2011). Three forms of trust and their association. European Political Science Review, 3(2), 169-200.

Newton, K., Stolle, D., \& Zmerli, S. (2018). Social and political trust. In E. M. Uslaner (Ed.), The Oxford handbook of social and political trust. Oxford University Press.

Nowell, L. S., Norris, J. M., White, D. E., \& Moules, N. J. (2017). Thematic analysis: Striving to meet the trustworthiness criteria. International Journal of Qualitative Methods, 16, 1-13.

Paoletti, E. (2011). Migration and foreign policy: The case of Libya. The Journal of North African Studies, $16(2), 215-231$.

Pargeter, A. (2012). Libya: The rise and fall of Qaddafi. Yale University Press.

Putnam, R. D. (2000). Bowling alone: The collapse and revival of American community. Simon and Schuster.

Rydgren, J., Sofi, D., \& Hällsten, M. (2013). Interethnic friendship, trust, and tolerance: Findings from two north Iraqi cities. American Journal of Sociology, 118(6), 1650-1694.

Schwegler, U., \& Smith, R. L. (2012). Ethno-political conflict in Kosovo: Cultivating trust in SerbianAlbanian post-conflict peace building. In D. Landis \& R. D. Albert (Eds.), Handbook of ethnic conflict: International perspectives (pp. 349-381). Springer.

Sliep, Y. (2014). Healing and integrated development as part of peacebuilding in post-conflict areas: A social capital lens. In S. Bongani Maphosa, L. DeLuca, \& A. Keasley (Eds.), Building peace from within (pp. 53-74). Africa Institute of South Africa.

Spiteri, D. (2012). The evolving identities of unaccompanied young male asylum seekers in Malta. Journal of Immigrant \& Refugee Studies, 10(4), 362-379.

Tam, T., Hewstone, M., Kenworthy, J., \& Cairns, E. (2009). Intergroup trust in Northern Ireland. Personality and Social Psychology Bulletin, 35(1), 45-59.

Togeby, L. (2004). It depends... how organisational participation affects political participation and social trust among second-generation immigrants in Denmark. Journal of Ethnic and Migration Studies, 30(3), 509528.

Tondini, M. (2010). 'Fishers of men? The interception of migrants in the Mediterranean Sea and their forced return to Libya', INEX Paper. October 2010.

Tsourapas, G. (2017). Migration diplomacy in the Global South: Cooperation, coercion and issue linkage in Gaddafi's Libya. Third World Quarterly, 38(10), 2367-2385.

Ullmann-Margalit, E. (2017). Trust, distrust, and in between. In E. Ullmann-Margalit, A. Margalit, \& C. R. Sunstein (Eds.), Normal rationality: Decisions and social order. Oxford University Press.

UNHCR. (2010). 'Convention and protocol relating to the status of refugees'. Accessed 9 June 2020. Via: https://www.unhcr.org/uk/3b66c2aa10.

UNHCR. (2017). 'QIPs: Libya'. October 23, 2017. Accessed 12 July 2019. https://www.unhcr.org/uk/libya. html.

UNHCR. (2020). Situation of human rights in Libya, and the effectiveness of technical assistance and capacity-building measures received by the Government of Libya. A/HRC/43/75. Accessed 13 Oct 2020. https://undocs.org/en/A/HRC/43/75.

UNSMIL. (2016). "'Detained and dehumanised": Report on human rights abuses against migrants in Libya'. (December 13 2016). Accessed 15 Oct 2020. https://www.ohchr.org/documents/countries/LY/ DetainedAndDehumanised_en.pdf.

Uslaner, E. M. (2002). The moral foundations of trust. Cambridge University Press. 
Van De Walle, S., \& Six, F. (2014). Trust and Distrust As Distinct Concepts: Why studying distrust in institutions is important. Journal of Comparative Policy Analysis, 16(2), 158-174.

Vandewalle, D. (2012). A history of modern Libya. Cambridge: Cambridge University Press.

Vandewalle, D. (2015). Revolution and authoritarianism in North Africa. In P. Cole \& B. McQuinn (Eds.), The Libyan revolution and its aftermath (pp. 17-31). Oxford University Press.

Zakarriya, J. (2018). Militarised cultures, disgraced bodies, and autocratic securities. Third World Thematics, 3(2), 196-211.

Zambakari, C. (2016). The misguided and mismanaged intervention in Libya: Consequences for peace. African Security Review, 25(1), 44-62.

Zetter, R. (2007). More labels, fewer refugees: Remaking the refugee label in an era of globalization. Journal of Refugee Studies, 20(2), 172-192.

Publisher's Note Springer Nature remains neutral with regard to jurisdictional claims in published maps and institutional affiliations. 